Joachim Migl:

\title{
Erwerbung der Einbandsammlung Max Hettler
}

\section{Erwerbung}

Im Februar 2001 konnte mit dem Ankauf der Einbandsammlung Max Hettler eine Erwerbung unter Dach und Fach gebracht werden, die bereits eine längere, Ende 1999 beginnende Vorgeschichte hat. Damals bot Frau Elisabeth Hettler, die Witwe des schon 1969 verstorbenen Stuttgarter Verlegers Max Hettler, der Landesbibliothek die Büchersammlung zum Kauf an. Besichtigung und Bewertung der Bibliothek, die Verhandlungen über den Kaufpreis und die Frage der Finanzierung zogen sich über längere Zeit hin, bevor im letzten Quartal des Jahres 2000 die Erwerbung fast ausschließlich mit eigenen Mitteln in den Bereich des Möglichen rückte. Es hatte vor diesem Hintergrund schon etwas Tragisches, dass Frau Hettler, der sehr an einer Übernahme des Buchensembles durch eine öffentliche Bibliothek gelegen war, genau in dem Moment, als die Entscheidung im Hause fiel, ins Krankenhaus gebracht werden musste und kurze Zeit später verstarb. Dass die Entscheidung letztlich doch noch in ihrem Sinne fiel, hat sie leider nicht mehr erleben können. Glücklicherweise fühlten sich ihre Erben der Sammlung und dem Willen von Frau Hettler so verpflichtet, dass die vereinbarten Bedingungen dann ganz ohne irgendwelche Komplikationen doch noch in einen Kaufvertrag umgesetzt werden konnten. Auf diese Weise erwarb die Bibliothek eine Sammlung von 333 Titeln.

\section{Die Sammlung}

In seiner Sammlung trug Max Hettler über mehrere Jahrzehnte hinweg schöne, künstlerisch und handwerklich bemerkenswerte Einbände zusammen.
Den eigentlichen Kern der Sammlung machen ca. 150 Stücke aus den Jahren ab 1893 aus, wobei ein besonderer Schwerpunkt auf den 20er Jahren des 20. Jahrhunderts liegt. Im engeren Sinne wird man diese 150 Exemplare als Zentrum ansehen können.

Darüber hinaus fügte Hettler aber noch viele andere Einbände, auch aus früheren Zeiten, in seine Sammlung ein. So haben wir auch viele Bücher des 16.19. Jahrhunderts übernommen, bei denen es auf der Hand liegt, dass sie für uns hauptsächlich wegen der enthaltenen Drucke von Interesse sind.

Alle Bände sind durchweg in einem erstklassigen Erhaltungszustand. Natürlich wird man von einer vergleichsweise kleinen Sammlung nicht erwarten können, dass in ihr die Geschichte der Einbandkunst, oder wenigstens die des 20. Jahrhunderts, repräsentativ dokumentiert wird. Vielmehr spiegeln sich in inr der subjektive Geschmack und das persönliche Beziehungsgeflecht des Sammlers wider.

Nicht selten lohnt der Blick über den Einband hinaus in das Buchinnere: Hier verbergen sich viele Pressendrucke, manche bibliophile Kostbarkeiten und äußerst wertvolle Ausgaben.

Wer sich einen Eindruck von der Sammlung verschaffen will, sei auf den Katalog einer Ausstellung der Einbandsammlung Hettler von 1991 (Sig. In der WLB: 41/90211) verwiesen bzw. auf den Sommer dieses Jahres vertröstet, wo ein Teil der Bibliothek in einer Ausstellung im Buchmuseum zu sehen sein wird. Fürs erste hier aber schon einmal ein paar „Appetithäppchen“. 